\title{
Reflexões sobre a cultura no pensamento social de Celso Furtado e na construção do método histórico-estrutural: um diálogo com a Sociologia e a Antropologia*
}

\author{
Reflections on culture in the social thought of Celso Furtado and in the construction of \\ the historical-structural method: a dialogue with Sociology and Anthropology
}

\author{
Tiago Macedo Bezerra Maia \\ Professor do Instituto Federal de Pernambuco (IFPE) \\ tiago.maia@vitoria.ifpe.edu.br
}

\section{João Morais de Sousa}

Professor da Universidade Federal Rural de Pernambuco (UFRPE)

joaomsousa@uol.com.br

\begin{abstract}
Resumo Este artigo tem o objetivo de elucidar a importância da aproximação e do diálogo de Celso Furtado (1920-2004) junto as ciências sociais, mais especificamente com a sociologia e a antropologia, ao inserir a cultura como ideia central em seus estudos e lançar uma luz compreensiva num dos elementos fundamentais que constituem o seu pensamento social: o método históricoestrutural. Neste sentido, o foco será a construção da problematização furtadiana sobre a cultura, basilar no seu pensamento e na sua busca de uma intepretação do subdesenvolvimento brasileiro. Por ser uma pesquisa de cunho teórico, a metodologia utilizada foi a qualitativa, que se configurou na revisão bibliográfica-documental. Ao evidenciar a centralidade temática da cultura nas reflexões furtadianas, espera-se poder contribuir para futuras pesquisas quanto a atualidade das críticas sociais deste intelectual nordestino, sempre comprometido com prementes mudanças estruturais para a América Latina e para o Brasil.
\end{abstract}

Palavras Chaves: Pensamento social e cultural de Celso Furtado; Método históricoestrutural; Subdesenvolvimento.

\begin{abstract}
This article aims to elucidate the importance of Celso Furtado's approach and dialogue (1920-2004) with the social sciences, more specifically sociology and anthropology, by inserting culture as a central idea in his studies and shedding a comprehensive light on one of the fundamental elements that constitutes his social thought: the historicalstructural method. In this sense, the focus will be on the construction of the furtadian problematization about culture, basing its thought and its search for an interpretation of Brazilian underdevelopment. As a theoretical research, the methodology used was qualitative, which was configured in a bibliographic-documentary review. By highlighting the centrality of culture in the furtadian reflections, this study aims to contribute to future research regarding the presenteness of the social criticism of this northeastern intellectual, always committed to structural changes for Latin America and Brazil.
\end{abstract}

Keywords: Celso Furtado's Social and cultural Thought; Historical-Structural Method; Underdevelopment.

\footnotetext{
* Este artigo é um dos frutos parciais de uma pesquisa maior sobre a temática da cultura popular pernambucana em realização pela profícua parceria de estudos e pesquisas firmada entre a Universidade Federal Rural de Pernambuco (UFRPE) e a Universidade Federal de Pernambuco (UFPE), no âmbito do Grupo de Pesquisa em Ensino de Ciências e Contemporaneidade (GECIC/DED/UFRPE/CNPq), que colabora mutuamente com o Grupo Interdisciplinar de Estudos sobre Representações Sociais e Educação (GIERSE/CE/UFPE/CNPq). Iniciada no ano de 2017 e até o ano corrente de 2020, está em andamento, pois foi projetada para ter continuidade e ser concluída no ano de 2022.
} 
O humano só pode ser compreendido pelo humano - até onde pode ser compreendido; e compreensão importa em maior ou menor sacrifício da objetividade [...]. (Gilberto Freyre)

\section{Introdução}

Celso M. Furtado (1920-2004) nasceu em Pombal, na Paraíba, nordeste do Brasil. Se fez um pensador humanizado e sensível às dores e sofrimentos do seu povo, mas também um homem cosmopolita, interdisciplinar e orientado por sua notória e sempre atual engajada erudição, que ao apontar para as origens e a formação dos problemas socioeconômicos latino-americanos, prenunciava caminhos, abria sendas e iluminava veredas que se nutriam de esperança na transformação do corpo social brasileiro. Furtado, apresenta e com maestria dispõe de tudo isso a compor seu pensar, assim é também considerado um dos mais completos intelectuais brasileiros do Século XX, sendo prestigiado e estudado no Brasil e em todo o mundo (SOUSA, THEIS e BARBOSA, 2020).

Bacharel em Direito (Ciências Jurídicas e Sociais) no Rio de Janeiro e Doutor em Economia (Ciências Econômicas) em Paris, em sua vida acadêmica, esteve também ligado e visitando, durante toda sua trajetória de pesquisas e escrita de obras, muitas outras Universidades reconhecidas internacionalmente como Yale e Northwestern (esta última, principalmente, em virtude de sua amizade com Melville Herskovits (1963), para efeito deste trabalho, pois o antropólogo americano era professor e pesquisador desta instituição) nos EUA, dentre várias outras americanas e de todo o mundo, por exemplo.

Nesse percurso, Furtado construiu seu caminho interdisciplinar através do qual estabeleceu o diálogo profícuo da economia com a filosofia, a literatura, a história, a geografia, dentre outras disciplinas, em especial neste estudo, mais especificamente, com a antropologia e a sociologia, dentre as ciências sociais (BORJA, 2013). Na sua vida pública, participou ativamente e integrou os quadros do Estado e da política no Brasil, legando importantes contributos, inclusive, como Ministro do Planejamento, no governo de João Goulart, entre os anos de 1962 a 1964, e, principalmente, como 
Ministro da Cultura, no governo de José Sarney, entre os anos de 1986 a 1988 (BORJA, 2019; D’AGUIAR, 2012).

Neste sentido, este trabalho conta com dois objetivos norteadores: evidenciar a importância da aproximação e do diálogo de Celso Furtado junto as ciências sociais, mais especificamente da sociologia e da antropologia; e, situar a centralidade da temática da cultura na construção do pensamento social furtadiano e em suas contribuições para a elaboração do método histórico-estrutural. Assim, ao perseguir, durante este escrito, tais objetivos, espera-se contribuir para uma melhor e mais aprofundada compreensão destas nuances no pensamento de Furtado.

O intelectual paraibano formulou a ideia de que, com a modernização crescente e a industrialização que gradualmente proporcionou uma forçosa transição, no Brasil, do modelo econômico primário exportador ao modelo econômico industrial de substituição de importações, há como pressuposto deste movimento econômico transicional técnico (do âmbito dos meios), elementos do modo de vida (do âmbito dos fins) da burguesia que desde o início da modernidade vinha, com o capitalismo, se expandindo e se consolidando, da Europa para todo o mundo (FURTADO, 1974; 1978).

Nessas iluminadoras entrelinhas supracitadas, Furtado começa, de uma forma mais geral, a colocar em evidência, deste modo, o rizomático lugar e o crucial papel da cultura que passa, na sua obra, a ser compreendida então como um sistematizado e complexo conjunto de valores e práticas que podem permear de sentido e significado o fazer e o agir, o pensar e o sentir em sociedade. A cultura surge, então, simbólica, autêntica e espontaneamente do modo de vida experienciado coletivamente no cotidiano e compartilhado socialmente, com a finalidade de materializar na concretude do real, os desejos e os ímpetos vislumbrados por um grupo ou um corpo social e que, por isso, se realiza em sociedade. Com isso, verifica-se, também, a característica finalística, para Furtado, das manifestações e fenômenos culturais.

Um outro aspecto que deve ser ressaltado para a compreensão da ideia furtadiana de cultura é que esta, como modo de vida (valor-fim) parece ser anterior, ou seja, implicada em, de alguma maneira, previamente anteceder e por isso preparar o espírito social e a cosmovisão coletiva refletida no caminho para o ensejo e estabelecimento dos (meios) materiais que chegam com a modernização técnica. Isso se deu, numa constatação histórica de Furtado, mostrada como uma fundamental conditio sine qua non como o a priori cultural que marcou a produção e a reprodução social $a$ 
posteriori das estruturas que edificaram as bases do poder econômico burguês advindo do capital (KORNIS, 2013).

As teorizações do economista nordestino sobre a cultura foram viabilizadas pela ousadia e pioneirismo deste intelectual que a todo instante, norteado por uma consciência mais ampliada e à frente da ciência de seu tempo, perseguia uma perspectiva mais global, aberta e conjunta, que, ao seu profícuo e singular modo, buscou fazer dialogar e integrar conhecimentos de diversas ciências humanas, ciências sociais e ciências sociais aplicadas, tornando assim, possível, um prisma fundado na criatividade interdisciplinar e na esperança engajada.

Deste modo, seguindo sua humanizada intuição que foi sendo também guiada por sua perspicaz reflexão científica, Celso Furtado, partindo de ideias de diversas correntes de pensamento, em alguns aspectos inclusive antagônicas (p. ex. Caio Prado Júnior e Roberto Simonsen), que espelhavam o espírito crítico de sua época, pôde assim elaborar suas importantes contribuições ao método histórico-estrutural. Isto para atender aos anseios de seu desbravar científico e em simultâneo poder melhor e mais profundamente desvelar as nuances das origens e dos desdobramentos dos processos e dos problemas do subdesenvolvimento latino-americano e brasileiro.

Este método foi chamado de histórico-estrutural e foi de suma importância para a legitimação acadêmica e científica de muitas das formulações teóricas de um grupo de pensadores dos problemas socioeconômicos da América do Sul e América Central. Esta corrente de pensamento sobre a sociedade e a economia da América Latina ficou conhecida como "Estruturalismo Latino-Americano", e teve Furtado como um de seus maiores expoentes.

De fato, enquanto o paraibano articulava e elaborava as bases de seus contributos ao método histórico-estrutural, mais se aproximava da centralidade temática da cultura em seu pensamento, e quanto mais aprofundava seus estudos sobre a cultura, mais se apropriava de ferramentas para consolidar essa metodologia em construção, ao mesmo tempo se municiava de argumentos teóricos e empíricos interdisciplinares para refutar as possíveis críticas vindouras desta elaboração. É diante desse panorama que este contexto será trabalhado no tópico 1 que se segue. 


\section{Uma crítica interdisciplinar aos limites das ciências econômicas na elaboração do método histórico-estrutural: Celso Furtado se aproximando da temática da cultura}

$\mathrm{Na}$ formação do pensamento furtadiano, está presente de modo acentuado o ímpeto de perscrutar o real e compreender os sentidos que nele mostram-se e que dele podem ser desvelados, enfrentando suas imbrincadas complexidades por meio de uma proposta interdisciplinar criativa e inovadora.

Sobre este acento vanguardista e criativo de interdisciplinaridade nas bases de seu pensamento, Furtado (1997), ele mesmo enuncia, já criticando a metodologia e o isolamento disciplinar e científico da economia, ao refletir e recordar que:

O pesado corpo da ciência econômica, concebido para funcionar em um universo onde a dimensão tempo inexiste, oferecia grande resistência [...]. Em torno dela pipocavam ideias novas vindas da história econômica, da demografia, da antropologia, da sociologia, da história da ciência e das técnicas. Em pouco tempo mais, [...] encontraria novo canal por onde desaguar. [...] impor-se-ia a necessidade de romper fronteiras e buscar a interdisciplinaridade, [...] de recolocar o problema epistemológico da relação entre fins e meios nas ciências [...] (FURTADO, 1997, t. 1: 197).

Este caráter interdisciplinar do pensamento furtadiano estará presente desde as suas obras iniciais até a sua maturidade reflexiva quando, inclusive, retomará em alguns momentos esta temática em obras como "Criatividade e dependência na civilização industrial" (1978) sobre a qual intérpretes atuais afirmam:

A démarche do diálogo com outras áreas do conhecimento, uma das marcas de sua obra, ganhou [...] ideias, que [...] podem interessar aos estudantes de ciências sociais com preocupações interdisciplinares. O livro teve versões em inglês, alemão, espanhol e francês. Seu aspecto mais fascinante é a visão histórica e filosófica que Celso apresenta ao ligar os conceitos de cultura e desenvolvimento. Trata-se de um livro de síntese e de aprofundamento das linhas principais de seu pensamento (QUINTELA et al., 2020: 63-64). 
Furtado, tendo estudado densa e profundamente a economia, disciplina na qual se especializou realizando seus estudos de pós-graduação, desfere contra este campo científico-disciplinar contundentes críticas na grande maioria das suas obras, principalmente, em virtude das limitações de objetividade e metodologia reducionista presente na maioria dos modelos econômicos, enfaticamente dedutivos e mormente quantitativos, segundo a sua visão, não obstante, economistas clássicos e neoclássicos figurarem de modo recorrente nas reflexões e obras furtadianas.

Ao definir como principal foco de seus estudos a problematização do desenvolvimento e o questionamento do subdesenvolvimento, de modo cabal ataca os limites objetivos e simplistas das ciências econômicas. E, comentando a origem de suas ideias e análises desenvolvimentistas, que ao evidenciar o fator "cultura", e certo de que para abarcá-lo, precisa ultrapassar as limitadoras fronteiras da economia, Furtado assim enuncia: “[...] a apreensão do fenômeno do desenvolvimento exigia um enfoque mais amplo do que nos permitia a análise econômica, pois estávamos lidando com um amplo processo de mudança cultural, "força criadora das civilizações"” (FURTADO, 1997, t. 1: 285).

Em seu diálogo com a sociologia, se aprofundou em autores clássicos do pensamento social tais como Max Weber (1967; 1992), por exemplo, que o aproximou da tradição reflexivo-interpretativa alemã dos fatos históricos, dos fatos sociais, das manifestações e dos fenômenos culturais. Com Weber, pôde passar a observar, sob o prisma da sociologia compreensiva e do individualismo metodológico do sociólogo germânico, a importância da compreensão da ação social e de seus sentidos individuais e como este agir, através das interações sociais, desvelam significados coletivos, e assim impactam na vida em sociedade.

Isso permitiu a Furtado entender, por exemplo, nesse eco weberiano, que, em certas sociedades, houveram fatores peculiares, práticos e simbólicos, no modo de vida e comportamentos de seus integrantes-membros que favoreceram a consolidação e a expansão do capitalismo. E, finalmente, pôde compreender e absorver, dentre estes fatores, um pouco mais da centralidade da cultura, esta como um sistema de símbolos criados pelo homem, na vida em sociedade, e sem os quais os homens não vivem socialmente, atrelando-se a este conteúdo simbólico-cultural que permeia de sentido e ilumina significados das práticas compartilhadas no cotidiano social.

Entre os sociólogos brasileiros que em alguma medida influenciaram Furtado, destaca-se aqui Gilberto Freyre (1957; 1969; 1990; 2010), dentre outros. Com o 
pernambucano Freyre, o intelectual da Paraíba pôde melhor adentrar na peculiar dinâmica da colonização europeia no nordeste do Brasil e na formação da sua sociedade açucareira primário-exportadora, bem como o modo que nela se davam as interações sócio-políticas e econômico-culturais, aspectos estes que viriam inclusive a ecoar como insights presentes na temática escolhida por Furtado em sua tese de doutorado "A economia colonial brasileira nos séculos XVI e XVII", defendida no ano de 1948, em Paris.

O economista paraibano atribuiu à cultura e às manifestações e fenômenos culturais, um papel destacado no processo do desenvolvimento social e econômico de uma sociedade, também sob influência da sociologia cultural freyreana. Em virtude disto, constata-se, em muitos aspectos de suas análises culturais, fortes influências da antropologia americana, tais como da escola antropológica difusionista cultural ou particularista histórica, de Franz Boas (1996; 2004), cujo pensamento seu aluno e discípulo Freyre foi contributário e, da escola antropológica interpretativa ou simbólica, de Clifford Geertz (1978; 1999; 2001), fortemente baseado em Max Weber, só para se mencionar aqui, inicialmente e dentre outros antropólogos estadunidenses.

É de grande valia sublinhar aqui, que a influência do pensamento freyreano nas reflexões furtadianas desta época não foram as únicas que motivaram ou ajudaram a direcionar sua visão quanto a importância dos estudos da cultura para a compreensão dos pilares constitutivos de uma realidade social, mas foi mais uma influência dentre várias outras. Sobre as relações de aproximação ou afastamento de Furtado quanto ao pensamento de Freyre, pode ser mencionado que ocorreu em variada gradação a depender da época que se analise, do recorte temporal, na obra e na reflexão furtadianas. Como exemplo, podem ser citados os textos de Bernardo Ricupero (2020) e Rosa Freire d'Aguiar (2015), nos quais ambos os autores buscam evidenciar pontos de encontro e de influxo entre Furtado e Freyre, demarcando alguns elementos de influência e outros de contraposição.

Porém, assinala-se, neste sentido também, guardadas as devidas proporções da receptividade ou assimilação e/ou crítica ou distanciamento de Freyre nas ideias de Furtado, salientam-se algumas questões para conduzir uma reflexão mais acurada sobre este ponto a serem enfrentadas, por exemplo, em trabalhos posteriores: em que medida Furtado torna Freyre presente em sua tese de doutorado, já que tanto no trabalho doutoral furtadiano como na Casa Grande e Senzala freyreana os recortes espaciais e temporais mais amplos são os mesmos, o Brasil colonial dos séculos XVI e XVII? De 
que modo as marcantes leituras de Gilberto Freyre contribuíram para que Celso Furtado construísse a sua perspectiva na busca de uma interpretação da formação do Brasil colonial? Porque, por exemplo, dentre as várias tendências e correntes do pensamento socioantropológico e cultural norte americano, Furtado buscou aproximar-se de autores com forte acento da teoria difusionista americana da cultura, tais como Ralph Linton e principalmente, Melville Herskovits (1963), que foram alunos e discípulos de Boas, tanto quanto Gilberto Freyre, e que guardadas as suas particularidades, todos expressam a influência deste referencial antropológico.

Boas (1996; 2004), constrói seu pensamento antropológico a partir das noções de difusão cultural e ciclos (círculos) de cultura. $\mathrm{Na}$ antropologia difusionista boasiana, há espaços que são também centros geográficos que concentram a matriz da vitalidade cultural de uma dada sociedade que, ao manifestarem seus fenômenos, irradiam e difundem essa cultura e assim expandem em ciclos temporais (circularmente/ciclicamente), ampliando no tempo-espaço os raios de influência e impacto dos rudimentos basilares deste corpo sociocultural. Deste modo, ocorreria a difusão das culturas, tal como o nome da escola indica e pressupõe.

Um outro ponto importante para Boas $(1996 ; 2004)$ é que a construção histórica dos hábitos e práticas compartilhados na vida social, devem ser abordados em suas específicas particularidades contextuais, e daí também se deriva um dos nomes desta corrente antropológica, também conhecida como particularismo histórico. Salienta-se que a influência de Boas no pensamento de Furtado foi de algum modo, ao mesmo tempo, introduzida e reforçada pelas leituras e estudos das teorias sociológicas e culturais de Gilberto Freyre $(1957 ; 1969 ; 1990 ; 2010)$ (que foi aluno de Boas nos EUA), mas é certo que ambos estiveram presentes como reverberações na construção de sua metodologia de análise e compreensão das sociedades latino-americanas e da formação social brasileira.

Então, se verifica que é possível perceber uma certa influência de Freyre, sua sociologia da cultura e antropologia cultural, e através deste cientista social pernambucano, também de Boas, para o economista paraibano Furtado. O sociólogo de Apipucos também foi uma referência furtadiana desde a mais tenra idade de adolescente, sendo anterior, inclusive, a seus estudos econômicos, como o próprio economista testemunha e explicita em trecho das "Aventuras de um economista brasileiro" (FURTADO, 1997), em que ele próprio explicita e confirma a hipótese tal como também demonstra César Bolaño (2015) abaixo, por exemplo, pois Furtado: 
[...] reconhece a influência [...] "norte-americana" da teoria antropológica da cultura [...] pela primeira vez por intermédio do livro de Gilberto Freyre, "Casa grande e senzala", aos 17 anos de idade, esclarecendo, não obstante, que [...] sua importância [...] revelou todo um instrumental novo de trabalho [...]. Esse instrumental novo, a teoria antropológica da cultura, estava presente, portanto, no pensamento de Furtado, desde as suas primeiras leituras, ainda na adolescência. Mais ainda, a sua ideia de cultura antecede a economia [...] (BOLAÑO, 2015: 93).

No âmbito da igualmente americana antropologia interpretativa ou simbólica de Geertz $(1978 ; 1999 ; 2001)$, esta se baseia, tal como Furtado, na perspectiva de cultura sociológico-compreensiva das ideias de Max Weber $(1967 ; 1992)$. Esta abordagem analisa os fenômenos e manifestações culturais como redes de sentido e símbolos criados, significados compartilhados, articulados e legitimados pelas práticas e costumes, saberes e comportamentos, fazeres e hábitos, como modos de vida próprios e autênticos de uma sociedade.

Partindo disso, Geertz (1978; 1999; 2001), utilizando das contundentes críticas da fenomenologia e da hermenêutica direcionadas à razão moderna e ao viés científico das teorias antropológicas clássicas que desta racionalidade derivaram, propõe uma antropologia que não se baseia no superficial e limitado objetivismo do ímpeto científico da modernidade. Geertz, então, aponta para a densidade das singularidades subjetivas que, ao interagirem socialmente, se compreendidas, podem desvelar a profundidade de uma cultura através de seus símbolos, forjados em hábitos e valores coletivos, como modo de vida, a cultura é tecida tal como uma obra de arte, permeando de sentido e plasmando de significados, assim, as vivências e experiências socialmente compartilhadas.

É na busca do acesso a este denso complexo de sentidos individuais e significados coletivos simbólico-social e culturalmente presentes no modo de vida da coletividade, que Geertz (1978; 1999; 2001) aplica pressupostos compreensivos fenomenológico-hermenêuticos, para acender a clareira iluminadora da densa interpretação cultural.

Em vários momentos de sua obra, Furtado faz uso de termos e construções reflexivas, no tocante às limitações metodológico-objetivas das ciências econômicas e da racionalidade científica, por exemplo, que remetem à fenomenologia e à 
hermenêutica, indiretamente, mas que, também, pode se admitir, por isso, que a análise furtadiana da cultura seja compreendida, num viés antropológico-interpretativo, como o das ideias de Geertz.

Isto posto, resgatando no tocante ao que se compreende como interdisciplinaridade, também sob a perspectiva de Celso Furtado, pode-se pontuar que:

A palavra interdisciplinaridade refere um modo de trabalhar o conhecimento [...] orientado pela reintegração dos aspectos que ficaram isolados ou dispersos em razão de certo tratamento dito disciplinar. [...] é justamente uma visão não fragmentada, ampla e por isso mesmo mais adequada à realidade [...]. Em suma, a interdisciplinaridade busca compensar a fragmentação do saber que decorre não da realidade, mais dos meios que dispomos para conhecê-la. Em última análise, o que a interdisciplinaridade busca recompor [...] é a própria realidade em sua irredutível complexidade (OLIVEIRA, 2018: 198).

Neste sentido e por tudo isso, no horizonte compreensivo da sociedade e da cultura brasileiras, Furtado pode ser considerado, também, um dos grandes intelectuais intérpretes do Brasil do século XX, e, com certeza, pode-se dizer que ele é um dos expoentes do chamado "pensamento social brasileiro" (SOUSA, THEIS e BARBOSA, 2020).

Após se revisitar e reconstruir um pouco do caminho e da influência do conhecimento antropológico sobre a cultura e as suas correntes americanas na perspectiva interdisciplinar do pensamento furtadiano, bem como se resgatar de modo sucinto, também, como se deu o legado da sociologia e da antropologia e sua recepção em Furtado, entra em cena agora a análise de uma de suas grandes contribuições para as ciências sociais e sociais aplicadas, o método histórico-estrutural, situando a cultura, a partir deste, como elemento angular no prisma metodológico do estruturalismo latinoamericano, em construção.

Celso Furtado, com todas as disciplinas (campos científico-disciplinares) que estavam em seu horizonte de formação, de estudos e de pesquisas, delas muito recepcionou de modo a estabelecer um frutífero diálogo entre as mesmas, mas, sempre tecendo contundentes críticas a essas, ou seja, não apenas reproduziu ideias na construção de suas teorias e métodos, mas, ao recebê-las, as articulou de um modo 
peculiar e próprio no seu visionário projeto de compreensão, enfrentamento e transformação da realidade das sociedades latino americanas, com foco na mudança social, política e cultural do Brasil e seu potencial de desenvolvimento.

Ainda sobre esta interdisciplinaridade, notadamente presente na reflexão furtadiana, ressalta-se que:

A postura interdisciplinar se dá por meio de um diálogo que articula os olhares de diversas disciplinas. É da ordem do conhecimento [...] confrontado com os objetos. Acontece que os objetos não existem atomisticamente separados e isolados. Eles existem numa rede, o que os insere numa totalidade, são sempre partes de um todo. Formam uma teia de significações que se interpenetram umas nas outras. Não de forma mecânica. É por isso que se fala da complexidade do real. O real não é simples. Ao isolarmos os objetos em múltiplas ciências, estamos tentando separá-los de sua unidade no todo. $\mathrm{O}$ olhar de uma única ciência não esgota o conteúdo significativo de um objeto, por mais que se possa isolá-lo. Mas também não basta somar, justapondo-os, múltiplos olhares. O olhar interdisciplinar procura exatamente recompor o tecido do real, na sua complexidade, tramando os significados (SEVERINO, 2011: 85).

Sobre a origem da metodologia utilizada por Celso Furtado: "[...] no momento da gênese do método histórico-estrutural, [...] estava empenhado justamente em defender uma visão interdisciplinar do problema do desenvolvimento, com ênfase na necessidade de incorporação de um paradigma antropológico [...]” (BOLAÑO, 2015: 99).

Furtado, em suas análises, leva em consideração os fatores históricos, sociais políticos e culturais constitutivos das particularidades, especificidades e singularidades de uma sociedade, especialmente, das sociedades da América Latina. Por isso, foi uma grande contribuição tal metodologia furtadiana para uma compreensão mais profunda da realidade, das nuances formadoras da sociedade brasileira. Logo, trata-se de uma abordagem que parte do princípio de que as regiões ou países possuem suas características heterogêneas próprias e estas precisam ser compreendidas nas peculiaridades dos fatores e condicionantes históricas das estruturas políticas, sociais, econômicas e culturais que necessitam, ensejam e apontam (RODRÍGUEZ e BURGUEÑO, 2007). 
Neste sentido, Furtado está assinalando que não há um modelo econômico único que se adeque e satisfaça toda e qualquer sociedade. Cada território, cada povo, cada cultura, cada meio social tem as singularidades que são próprias de sua formação temporal e espacial, de forma que vive suas particularidades, possui especificidades histórico-geográficas e político-culturais que não podem se submeter a nenhum simplismo ou reducionismo de modelos científicos generalizadores e disciplinarmente autocentrados, como nas metodologias normalmente mais utilizadas pelas ciências econômicas.

Diante disso, é importante ser ressaltado que, ainda à época da construção dos pensamentos de Celso Furtado e da difusão do estruturalismo latino-americano, as metodologias econômicas pretendiam explicar o desenvolvimento à luz de uma tendência simplificadora e objetivadora, tal como parece sublinhar o próprio Celso Furtado, de modo que:

[...] Em síntese: a interação da economia com o não econômico, seguramente o que é mais importante no processo de desenvolvimento, desaparece do campo de observação do economista. O que no começo era uma simplificação metodológica necessária tende a transformar-se em obstáculo à própria percepção da natureza do problema [...] (FURTADO, 2003: 102).

Por outro lado, o método histórico-estrutural utilizado por Furtado busca uma compreensão do todo observando as partes, levando em consideração que o sistema econômico internacional apresenta hierarquias e assimetrias econômicas e de poder regionais e locais que o fundam e estruturam, focando assim, no contexto histórico de maneira específica nas partes e suas relações constitutivas e de formação. Ao analisar a dinâmica desses processos econômicos no tempo e no espaço e tendo como fio condutor analítico a procura do entendimento do todo que envolve os processos sociais, políticos e culturais, conexos e contextualizados, Furtado busca aí estabelecer, entre esses elementos de suas reflexões, conexões e contextualizações (RODRÍGUEZ, 2009).

Assim, as contribuições deste novo aporte metodológico:

[...] resultam da fundamentação das análises na consideração de características particulares [...] e da aplicação do método histórico-estrutural, que ao incorporar análises historicamente contingentes com dimensões nãoreducionistas [...] uma concepção de mundo que considera mais do que 
fatores meramente econômicos. Ademais, cumpre destacar a contribuição original quanto à compreensão do desenvolvimento e do subdesenvolvimento na condição de processos mutuamente constituídos dentro de um mundo economicamente integrado [...] (MISSIO, JAYME JR e OREIRO, 2012: 28-29).

Sobre as contribuições de Furtado na construção do método histórico-estrutural, como instrumento viável de interpretação e de possível transformação no cenário do subdesenvolvimento da América Latina e do Brasil, deve ser considerado ainda, que:

A tarefa de pensar o subdesenvolvimento latino-americano, [...] exigia, por um lado, a leitura crítica da produção teórica sobre a temática do desenvolvimento nas diferentes correntes de pensamento em voga para não incorrer num particularismo excludente $\mathrm{e}$, por outro, aprofundar $\mathrm{o}$ conhecimento empírico da realidade latino-americana, aprendendo com ela. Tinha-se muito claro que só assim seria possível ensaiar uma interpretação do subdesenvolvimento latino-americano capaz de instrumentalizar decisões práticas com o objetivo de sua superação. [...] Já estava posto àquela época que não havia, pois, como pensar o subdesenvolvimento sem esforço analítico totalizador. Era indispensável partir de uma perspectiva analítica integradora, tanto do ponto de vista dos diferentes aspectos da realidade e das distintas realidades [...] latino-americanas, como também das diferentes disciplinas das ciências sociais (SANTOS, 2011: 59-60).

Em suma, esse novo método aplicado pelos intelectuais cepalinos do estruturalismo latino-americano, mostra:

Um esquema analítico adequado para o estudo do desenvolvimento e do subdesenvolvimento, [...] observação $[\ldots]$ sistemática na qual o subdesenvolvimento é parte do processo histórico global de desenvolvimento, [...] tanto o subdesenvolvimento como desenvolvimento, são duas faces de um mesmo processo histórico universal; [...] ambos os processos são historicamente simultâneos, [...] estão vinculados de modo funcional, ou seja, [...] interatuam e se condicionam mutuamente [...] (SUNKEL e PAZ, 1970: 37. Tradução livre dos autores). 
Nesse contexto de elaboração do método histórico-estrutural faz-se importante, para uma melhor compreensão do estruturalismo latino-americano, destacar que:

Convencido de que as disparidades entre as economias se devem não apenas a fatores econômicos, porém, mais ainda, à diversidade de matrizes culturais e peculiaridades históricas, Celso teorizou sobre os fatores culturais e sua influência no processo de subdesenvolvimento latino-americano. Excetuando-se a dominação colonial, o fenômeno da dependência se manifestava inicialmente, a seu ver, na área cultural. Trocando em miúdos: (a) o capitalismo periférico gerava um mimetismo cultural, provocando uma permanente concentração de renda e reforçando, por sua vez, a dependência cultural; (b) os padrões de consumo eram transplantados dos países mais ricos para os mais pobres; (c) os padrões de consumo conspícuo das elites latino-americanas eram (são) um fator de perpetuação do subdesenvolvimento (QUINTELA et al., 2020: 69).

Isto posto, no próximo tópico 2 deste artigo, se buscará apresentar de modo mais detido e aprofundado a noção de cultura, no pensamento de Celso Furtado, se evidenciando, com o uso intrínseco do método histórico-estrutural, a importância crucial da perspectiva cultural para a consolidação de suas reflexões sobre o (sub)desenvolvimento, destacando o potencial da cultura como fonte possível de criatividade e um ponto norteador dos horizontes para a transformação social no Brasil.

\section{A cultura em evidência nas reflexões de Celso Furtado: a perspectiva cultural furtadiana e sua inovadora problematização do (sub)desenvolvimento}

A relevância do pensamento de Furtado sobre a cultura está em ele refletir contextualizada e criticamente, no sentido de desvelar nuances pioneiras acerca do promissor potencial criativo das autênticas e identitárias manifestações e fenômenos culturais, num prisma interdisciplinar, como já anteriormente mencionado, analisado e compreendido à luz do método histórico-estrutural.

O pensar cultural furtadiano pode proporcionar, também, assim, uma compreensão mais profunda dos sentidos e dos significados dos modos de vida, hábitos, costumes, práticas, saberes, tradições, valores, fazeres e símbolos culturalmente 
compartilhados que formam, socialmente, as diversas culturas como as presentes na América Latina e no Brasil.

Desse modo, torna-se fundamental a reflexão sobre o papel das manifestações e fenômenos culturais, ressaltando seus potenciais identitários criativos para o possível desenvolvimento econômico e social, em âmbito local, regional ou nacional, ponto de encontro com a ideia de cultura de Furtado.

A preservação e valorização da cultura, figura, então, como uma urgência para que a sociedade brasileira atinja um estágio satisfatório, mais amplo, genuíno e pleno de independência, criatividade e desenvolvimento, também numa perspectiva furtadiana.

Celso Furtado, então, se propõe a enfrentar o problema de identificar qual o impacto da economia na elaboração de uma reflexão sobre a cultura, e, ao mesmo tempo, explicitar qual a força criativa da raiz cultural que pode impulsionar e conduzir ao pleno desenvolvimento, a América Latina, com foco no Brasil (D’AGUIAR, 2013).

O pensamento furtadiano sobre os aspectos culturais se elabora então, refletindo sobre os contextos em que o diálogo cultura-economia pode ser verificado no fluxo do tempo e na dinâmica do espaço. Assim, se desvela e elenca o potencial cultural, ponto crucial eivado de possibilidades de impactos diversos, também, sobre a construção das pressuposições sobre as quais se edificarão os pilares de mais viáveis e mais novos modelos econômicos que considerem esses parâmetros culturais. Furtado procura, de tal modo, realocar as temáticas da cultura, retirando-a da periferia na modelagem econômica, e, dando-a visibilidade na pretensão de alçá-la à centralidade nos debates sobre o (sub)desenvolvimento (KORNIS, 2013).

Neste ponto crucial, figurará como protagonista e fio condutor o aporte antropológico que chegou, na vida e na adolescência de Furtado primeiro, à frente portanto da economia, e, por isso, foi tão defendido e apreciado em muitas de suas obras, que categoricamente declara: “[...] posto que o subdesenvolvimento é uma manifestação cultural, era natural que antropólogos nos houvessem antecipado no terreno que agora explorávamos, não sendo pouco o que com eles tínhamos que aprender" (FURTADO, 1997, t. 1: 194).

Diante do polissêmico termo cultura, no ínterim das ciências humanas, sociais e sociais aplicadas, pode-se verificar que um dos seus mais notórios sentidos é o que a coloca como elemento que distingue o que é natural (disposto e dado na realidade pela natureza) e do homem (construído inventivamente e elaborado criativamente pelo ser humano, de modo situado no tempo e no espaço, para solução de seus problemas 
cotidianos e para satisfazer e realizar suas necessidades e anseios sociais) - note-se aqui, também, uma ênfase no potencial criativo e inventivo que surge da vida em sociedade.

Mas, explicitou Furtado, como argumento-base em muitos de seus escritos, que a economia, em geral, em grande parte de sua história como ciência, desconsiderou as manifestações e os fenômenos culturais, deixando a cultura fora de sua objetividade analítica, e, a cultura, assim, era relegada e excluída como fator/variável de impacto nos modelos econômicos mais usuais.

Desse modo, a economia buscou adequar e limitar o rico e ilimitado manancial da cultura e sua gama de possibilidades compreensivas, impondo ao âmbito cultural apenas e superficialmente modelos que foram objetiva, quantificada, racional e utilitariamente limitados e inapropriados, diante dos aspectos culturais (MIGUEZ e MACHADO, 2010; SILVA, 2007). Furtado tece essa crítica porque, para ele, de fato, as relações econômicas condicionam e são condicionadas, em simultâneo, pela cultura como modo de vida, no mundo capitalista da civilização industrial.

No século XVI, um vocábulo já existente e mais geral denominado de cultura foi tomado, em francês, ao que parece, com referência aos processos materiais de desenvolvimento humano e suas realizações (CUCHE, 1999). Com o fluxo temporal da história, passa de um sentido mais técnico francófono para uma palavra alemã que abrangeria, também e principalmente, aspectos espirituais, das potencialidades do pensar humano.

Ambos os significados falam de elaborações que surgem com as experiências e vivências sociais, então, o termo cultura estava ainda preso e cerceado em adjetivos que, como atributos de sua ideia, dava sentido a ela, mas, com o passar do tempo, foi liberto dessas limitações e tomado tal como forma ou modo de abstração em si mesma (EAGLETON, 2003). No século XVIII, essa perspectiva mais abrangente sobre a cultura será o seu prisma fundamental de compreensão e sentido, pois, eis que:

A ideia de cultura vem a aparecer em meados do ano de 1871. Considera-se a mesma como uma ideação sintética de duas noções anteriormente já existentes, a alemã Kultur e francesa Civilization. A noção germânica aponta para os conteúdos espirituais e simbólicos que fundam e plasmam o pensamento e a compreensão do sentido de uma cosmovisão compartilhada em um dado grupo social. A noção francófona liga-se mais às produções 
materiais surgidas do enfrentamento das necessidades práticas cotidianas por uma coletividade humana [...]. Edward Tylor então, em 1871, opera tal síntese na noção anglófona de Culture. Assim, Tylor consegue reelaborar e reunir numa única palavra todas as manifestações e fenômenos provenientes das realizações simbólicas e materiais do ser humano na sua vida social [...] (MAIA e SOUSA, 2019: 148).

E, nesse âmbito, é importante ter em mente, também, que:

Há consensos sobre o fato de que cultura é [...] a adaptação humana ao seu ambiente natural, que [...] é grandemente variável e [...] se manifesta em instituições, padrões de pensamento e objetos materiais. [...] inclui todos os elementos do legado humano [...] que foi adquirido [...] pela aprendizagem consciente, ou [...] técnicas de várias espécies, sociais ou institucionais, crenças, modos padronizados de conduta (SANTAELLA, 2003: 30-31).

Deste modo, as manifestações e fenômenos da cultura estão em um movimento de se construir, desconstruir e reconstruir constante e, um dos objetivos para aqueles que estudam a temática, seria desvelar tais fenômenos manifestos no mundo social tão rico de encobertos sentidos e significados, podendo então interpretá-los e compreendêlos.

Sobre isto, Furtado ajuda na elucidação da dinâmica das transformações e mudanças advindas dos processos culturais ao afirmar que: “[...] sendo a cultura um conjunto de elementos interdependentes, toda vez que em determinadas condições históricas avança a tecnologia e se desenvolvem as bases materiais, todos os demais elementos serão chamados a ajustar-se às novas condições, ajustamentos esses que darão origem a uma série de novos processos [...]” (FURTADO, 1964: 19).

Logo, é imprescindível partir desta perspectiva, de que a cultura não é só aprendida, mas também modificada, transformada através da inovação (MELLO, 2003), com o uso das faculdades da criatividade que emergem das experiências coletivas, em sociedade.

A cultura parece surgir, também, para que possam ser supridas as necessidades próprias oriundas de seus específicos contextos sociais, pelas soluções coletivas dadas às questões enfrentadas por cada grupo social, peculiarmente. Seja pelas tradições passadas, elementos que se enraízam e permanecem e, ao mesmo tempo, seja pelos 
novos dinâmicos e criativos conteúdos que, ao somarem-se, trazem inovações e mudanças ao cotidiano de uma sociedade, a cultura pode ser conceituada como "[...] um todo complexo que inclui conhecimentos, crenças, arte, moral, leis, costumes ou qualquer outra capacidade ou hábitos adquiridos pelo homem como membro de uma sociedade" (LARAIA, 1986: 25)

$\mathrm{Na}$ história da antropologia científica e, portanto, dos estudos sobre os temas culturais, enquanto Tylor apresentou um viés evolucionista etnocêntrico e unilateral da cultura das sociedades, Boas propôs uma reflexão diferente ao sugerir uma reconstrução mais ampla, histórica e geográfica das singularidades de uma sociedade, multilateralmente, portanto. Assim, as reflexões, percepções e experimentos sobre a antropologia, a ciência da cultura, foram ao longo do tempo, de interesse de nomes como Edward Tylor, Franz Boas, Bronislaw Malinowski e Claude Lévi-Strauss, dentre outros icônicos antropólogos (MAIA e SOUSA, 2019).

Assim, recorda-se também, aqui, mais sinteticamente, que Furtado (1984) concebe a cultura como um sistema de fins que articula em seu bojo um complexo de valores e símbolos que confere às práticas sociais e ao modo de vida seu horizonte de significados e sentidos cotidianamente vividos e compartilhados numa sociedade.

Sobre a caracterização sistêmica da cultura e inter-relacional dos seus elementos constitutivos, esclarece ainda Furtado, que:

A reação contra o caráter determinista ou teleológico das ideias de evolução e progresso, caras ao século XIX, fez surgir no campo da antropologia o conceito de mudança social. Concebendo a cultura como um processo, em que surgem modificações em um fluir permanente, os antropólogos passaram a preocupar-se com os fatores responsáveis por essas mudanças, estudando em detalhe, para uma determinada cultura, os elementos mais sujeitos a mudança. Esses estudos tanto restabeleceram o interesse pelos aspectos históricos da herança social como levaram a uma compreensão mais aguda da interdependência entre os distintos elementos materiais e não materiais que integram uma cultura. Demais, a percepção dessa interdependência [...] levou à compreensão da cultura como um sistema e abriu a porta às tentativas de aplicação de instrumentos de análise mais aperfeiçoados no estudo do comportamento desses sistemas [...] (FURTADO, 1964: 26). 
Ainda na primeira metade do século $\mathrm{XX}$, veio à tona, em todos os campos disciplinares e científicos, a crise da racionalidade e, junto a esta, a crise das ciências. Desta maneira, as reflexões fenomenológicas e hermenêuticas, em contraposição aos postulados epistemológicos vigentes, revelaram novas, mais amplas e mais profundas possibilidades de entendimento e compreensão dos fenômenos sociais e manifestações culturais em geral.

Neste sentido, tentando superar a superficialidade da ciência e propondo uma maior densidade no entendimento das questões culturais, Max Weber (1967; 1992), com sua sociologia compreensiva, elucida as bases de sua perspectiva ao afirmar que o homem é um animal que vive preso a uma teia de significados, uma rede de sentidos criada por ele mesmo, a cultura que, também, “[...] é um sistema de símbolos e significados. [...]” (LARAIA, 1986: 63).

E, são justamente esses emaranhados de símbolos que, ao serem sistematizados e compartilhados ao longo do tempo e num espaço, pelos integrantes de uma comunidade, formam a cultura e dão sentido à vida social. Este é o foco principal de toda atividade interpretativa antropológica, o conteúdo simbólico-cultural que pode ser, assim, compreendido, interpretativamente. De acordo com este pensamento:

[...] essa interpretação cultural é cabível para que se possa desvelar os sentidos originários e mais autênticos significados da cosmovisão, das tradições ancestrais e das práticas e dos saberes cotidianos de um povo, alcançando, deste modo, a densidade de uma cultura. Portanto, a atividade antropológico-interpretativa se daria como que adentrando em um texto, uma interpretação, para que se possa então compreendê-la, como uma arte, para acessar assim aos conteúdos espirituais constitutivos de sentido mais densos e assim se contrapor aos limites descritivos que a superficialidade da ciência não alcança (MAIA e SOUSA, 2019: 150).

Em vista da análise deste mosaico encadeado de sentidos e labirinto articulado de significados que é a cultura, Geertz $(1978 ; 1999 ; 2001)$ ensina que se deve elucidar esses sentidos e significações latentes mais rizomáticos e ancestrais das tradições, práticas e saberes, buscando relacioná-los quando vierem a emergir, também, como horizonte de compreensão $\operatorname{do}(\mathrm{s}) \operatorname{modo}(\mathrm{s})$ de vida partilhado(s) pelos membros integrantes de um grupo social. Interpretar a cultura, então, é “[...] tentar ler um 
manuscrito estranho, desbotado, cheio de elipses, incoerências, emendas suspeitas e comentários tendenciosos [...]" (GEERTZ, 1978: 20).

As teias de sentido da cultura crescem e se ampliam espontaneamente e criativamente, surgem mudanças e inovações naturalmente, sem que necessariamente aqueles que a produzem percebam claramente este movimento, esta dinâmica (GEERTZ, 1978; 1999; 2001). Para Geertz (1978), a cultura emerge e desvela-se contextualmente e, apenas tendo em vista este contexto singular, pode-se buscar decifrá-la de forma autêntica, inteligível, profunda e, portanto, densamente descritiva e compreensiva.

Assim, o antropólogo norte-americano, afirma, em síntese, que:

O conceito de cultura que eu defendo, [...] é [...], como Max Weber, que o homem é um animal amarrado a teias de significados que ele mesmo teceu, assumo a cultura como sendo essas teias e sua análise; portanto, não como uma ciência experimental em busca de leis, mas como uma ciência interpretativa, à procura do significado (GEERTZ, 1978: 15).

É importante ressaltar aqui que, se a cultura, por um lado "se operacionaliza como elemento prático e comportamental, instrumental e simbólico de superação das dificuldades e necessidades enfrentadas no cotidiano da vida social" (MAIA e SOUSA, 2019: 151), por outro, pode ser entendida como modo de vida capaz de assinalar a distinção entre grupos sociais, a partir da criatividade experienciada nas sociedades.

Sobre isto, e também sobre o potencial criativo das inovações culturais, percebese que:

Uma cultura, enquanto está sendo vivida, é sempre em parte desconhecida, em parte irrealizada. A construção de uma comunidade é sempre uma exploração, pois a consciência não pode preceder a criação, e não existe nenhuma fórmula para uma experiência desconhecida. Uma boa comunidade, uma cultura viva, irá, por causa disso, não apenas dar espaço para, mas encorajar ativamente, todo e qualquer um que possa contribuir para [...] a necessidade comum. Precisamos considerar com toda a atenção qualquer afeto, qualquer valor [...] (EAGLETON, 2003: 168). 
Mais uma vez, faz-se necessário recordar, já como anteriormente citado, que Furtado recebeu influência antropológica de Franz Boas (1996; 2004), através de alguns de seus alunos e discípulos, a exemplo do culturalismo, também de caráter interdisciplinar, presente nas obras sociológicas de Gilberto Freyre (1957; 1969; 1990; 2010), e nos estudos sobre mudanças sociais (e culturais) do também antropólogo americano Melville Herskovits (1963), com quem realizou pesquisas e estudos a partir de suas visitas aos EUA e a consequente consolidação da amizade entre eles, através de suas viagens, seus diálogos e trocas de correspondências.

Para Furtado (1974; 1978), investigar a expansão da civilização industrial burguesa europeia, ao espalhar, no mundo, seu modo e padrão de vida e consumo capitalista, é a pedra de toque da compreensão do subdesenvolvimento, entre os povos e as culturas. Neste sentido, faz-se, para ele, importante a antropologia de Herskovits (1963), pois:

A exemplo de outros antropólogos de sua geração, ele se inclinava a sobrepor uma 'lógica da cultura' à história, o que o levava a ver na inovação (e na descoberta) mais uma resposta do que uma mutação. Estava longe de deslizar para o determinismo cultural, mas dava ênfase à preexistência de uma 'base cultural', sem o que a inovação não seria absorvida e tampouco a mudança cultural se apresentaria ordenada. Do mesmo ponto de vista, assegurava que a difusão também seguia uma linha de menor resistência, de alinhamento com respeito à orientação preexistente. [...] (FURTADO, 1997, t. 1: 194-195).

No pensamento de Furtado $(1978 ; 1984)$ não se enseja, de modo algum, a desconsideração de estudos sobre como os diversos âmbitos culturais comportam-se e impactam economicamente, mas com a ressalva de que noções econômicas, com toda a sua limitação objetiva encerrada em modelos superficiais, não alcançam a compreensão das dimensões mais densas e profundas de uma cultura e da criatividade que lhe é intrínseca.

Estes aspectos que não tinham visibilidade para a ciência econômica clássica que nem os tangencia (a não ser instrumentalmente), são em exato o que Celso Furtado buscará evidenciar e fazer emergir com a sua noção de (sub)desenvolvimento numa perspectiva cultural, lançando assim nova luz para a necessidade do diálogo economia- 
sociologia-antropologia, que abre horizontes, possibilidades e novos caminhos para as constatações econômicas e o pensamento social, comprometidos com a urgente transformação do Brasil.

Justo por tudo isso é importante que aqui seja ressaltada a premente necessidade de terem sido abordados, ao longo de todo este texto, cada elemento essencial anteriormente mencionado para a compreensão de sua ideia de cultura, pois foi devido a articulação e integração conjunta e interdisciplinar dos mesmos, que proporcionou ao economista paraibano, mesmo perseguindo o horizonte da totalidade, ter mantido a firme visão nas particularidades dos objetos e temáticas por ele estudados e analisados. No contexto dos estudos furtadianos sobre a cultura, portanto, esses elementos e categorias aqui neste artigo apontados, são basilares para a compreensão da centralidade que Furtado atribui a mesma no liame dos processos inerentes à dinâmica do (sub)desenvolvimento.

Neste sentido, sublinha-se e reitera-se quanto as reflexões de Celso Furtado sobre a cultura, que:

Ele propõe um esforço intelectual e político de transformação social que, enraizado em nossas especificidades históricas, seja capaz de lograr a constituição de formas sociais mais acionadoras de nossa criatividade e diversidade cultural, "fazendo aflorar nossas energias contidas", para desmontar vigorosamente nossas desigualdades sociais e regionais. [...] O legado de seu programa de estudos e reflexões nos deixa também uma agenda política de ação [...] (QUINTELA et al., 2020: 143).

Percebe-se que se vive há mais ou menos uma década e mais ainda nos idos atuais de 2020, ano centenário do autor aqui estudado, em todo o Brasil, um "resgate das contribuições de Celso Furtado sobre a cultura" (ROCHA, 2012; SOUSA, THEIS e BARBOSA, 2020). Deste modo, é oportuno e necessário, mais que nunca antes, se debruçar e adentrar nos textos tão urgentes e de vivaz atualidade de Furtado e que tem especial utilidade quando se trata de se questionar sobre os sentidos e significados de cultura para enfrentar o subdesenvolvimento tal como marcadamente se perpetua na América Latina e no Brasil. 


\section{Considerações finais}

Este artigo procurou mostrar a evidente e notória atualidade do pensamento elaborado pelo economista paraibano Celso Furtado sobre a cultura e a centralidade desta reflexão cultural, objetivando ultrapassar as limitadas fronteiras do pensamento econômico de sua época, desde a construção do inovador e interdisciplinar método histórico-estrutural, com ênfase em sua interlocução junto à sociologia e à antropologia, de fundamental importância para o seu grupo de intelectuais que formou a corrente chamada, não por acaso, de estruturalismo latino-americano, no qual nacional e internacionalmente se destacou.

Ao aplicar o método pioneiro, buscou fazer emergir à compreensão toda a profundidade abissal e a densidade até então velada, numa lente histórica, da singular dinâmica dos elementos estruturais e principalmente das estruturantes interações culturais que foram constituídas mas que também constituíram e estruturaram, em simultâneo, as especificidades da formação econômica e social brasileira.

Com isso, Furtado ilumina os passos num caminho possível da urgente necessidade de transformação das formas do subdesenvolvimento da América Latina, sempre trazendo consigo, em suas reflexões críticas, o acento da esperança no potencial da criatividade da cultura para um autêntico desenvolvimento socioeconômico do Brasil.

Os autores desse trabalho esperam que os resultados obtidos nesse artigo possam contribuir na abertura de novos horizontes para novas pesquisas a adentrar e desbravar o plurifacetado interdisciplinar método furtadiano e o inovador multidimensional pensamento de Celso Furtado sobre a cultura.

\section{Referências bibliográficas}

BOAS, Franz (1996). A Arte Primitiva. Lisboa: Fenda. . (2004). Antropologia cultural. Rio de Janeiro: Jorge Zahar.

BOLAÑO, César Ricardo Siqueira (2015). O conceito de cultura em Celso Furtado. Salvador: Edufba.

BORJA, Bruno (2019). Desenvolvimento e política cultural: reflexões de Celso Furtado no caminho do Ministério da Cultura. Cadernos do desenvolvimento, Rio de Janeiro, vol. 14, n. 25, p. 39-56, jul./dez. Disponível em: http://www.cadernosdodesenvolvimento.org.br/ojs-

2.4.8/index.php/cdes/article/view/386. Acesso em 10 abr. 2020. 
(2013). A formação da teoria do subdesenvolvimento de Celso Furtado. Tese (Doutorado em Economia Política Internacional). Universidade Federal do Rio de Janeiro, Rio de Janeiro.

CUCHE, Denys (1999). A noção de cultura nas ciências sociais. Trad. Viviane Ribeiro. Bauru: EDUSC.

D’AGUIAR, Rosa Freire (Org.) (2012). Ensaios sobre cultura e o Ministério da Cultura. Rio de Janeiro: Contraponto / Centro Internacional Celso Furtado.

. (2013). Celso Furtado e a dimensão cultural do desenvolvimento. Rio de

Janeiro: E-papers / Centro Internacional Celso Furtado.

(2015). Celso Furtado - um retrato intelectual. Cadernos do desenvolvimento.

Rio de Janeiro v. 10, n. 17, Jul.-dez. p. 122-127.

EAGLETON, Terry (2003). A ideia de cultura. Lisboa: Ed. Temas e Debates (Coleção Memórias do Mundo).

FREYRE, Gilberto (1957). Casa-grande e senzala. Lisboa: Livros do Brasil. . (1969). Novo mundo nos trópicos. São Paulo: Nacional/EDUSP.

(1990). Sobrados e mucambos. Rio de Janeiro: Record.

(2010). O mundo que o português criou. São Paulo: É realizações.

FURTADO, Celso (1964). Dialética do desenvolvimento. Rio de Janeiro: Fundo de Cultura.

. (1974). O mito do desenvolvimento econômico. Rio de Janeiro: Paz e Terra.

. (1978). Criatividade e dependência na civilização industrial. São Paulo: Círculo do Livro.

. (1984). Cultura e desenvolvimento em época de crise. Rio de Janeiro: Ed. Paz e Terra.

. (2003). Raízes do subdesenvolvimento. Rio de Janeiro: Civilização brasileira 2003.

- A fantasia organizada. In: FURTADO, Celso. Obra autobiográfica de Celso Furtado: tomo I. São Paulo: Paz e Terra.

. (1997). Aventuras de um economista brasileiro. In: FURTADO, Celso. Obra autobiográfica: tomo II. São Paulo: Paz e Terra.

GEERTZ, Clifford (1978). A interpretação das culturas. Rio de Janeiro: Zahar. . (1999). O saber local: novos ensaios em antropologia interpretativa. Tradução Vera M. Joscelyne. Petrópolis: Vozes.

. (2001). Nova luz sobre a antropologia. Rio de Janeiro: Jorge Zahar.

HERSKOVITS, Melville Jean (1963). Antropologia cultural: man and his works. Tomo I. São Paulo: Mestre Jou.

. (1963). Antropologia cultural: man and his works. Tomo II. São Paulo: Mestre Jou.

KORNIS, George (2013). A cultura no pensamento (e na ação) de Celso Furtado: desenvolvimento, criatividade, tradição e inovação. Novos estudos - CEBRAP, São Paulo, n. 96, p. 165-171, jul.

LARAIA, Roque de Barros (1986). Cultura: um conceito antropológico. Rio de Janeiro: Zahar.

MAIA, Tiago Macêdo Bezerra \& SOUSA, João Morais de (2019). Contribuições da teoria das representações sociais e da teoria antropológica interpretativa para a compreensão dos símbolos da resistência religiosa afro-brasileira nos Maracatu Nação em Pernambuco. In: SILVA, Rejane Dias da; FREITAS, Vera Lúcia Chalegre de; SOUSA, João Morais de (Orgs.). Educação, formação docente e cultura: diálogos na perspectiva da teoria das representações sociais. Curitiba: CRV. 
MELLO, Luiz Gonzaga de (2003). Antropologia Cultural: iniciação, teoria e temas. 10. ed. Petrópolis: Vozes.

MIGUEZ, Paulo \& MACHADO, Ana Flávia (2010). Estudo 45: Diversidade cultural: valorização e difusão. In: BANCO NACIONAL DE DESENVOLVIMENTO ECONÔMICO E SOCIAL; UNIVERSIDADE FEDERAL DE MINAS GERAIS. Projeto PIS: perspectivas dos investimentos sociais no Brasil. 2010. Disponível em: http://www.bndes.gov.br/SiteBNDES/export/sites/default/bndes_pt/Galerias/Arqu ivos/conhe cimento/seminario/Car_ima_NE_PauloMiguez.pdf $>$. Acesso em 15 abr. 2020.

MISSIO, Fabrício J.; JAYME JR, Frederico G.; OREIRO, José Luís (2012). A tradição estruturalista economia. Disponível em: http://joseluisoreiro.com.br/site/link/3b4c257c6943e21b64ad04a29763cb3685ea7 215.pdf. Acesso em 22 abr. 2020.

OLIVEIRA, Cícero (2018). Ensino de filosofia, formação e interdisciplinaridade. Griot: Revista de Filosofia, Amargosa/Bahia, v.17, n.1, p.193-203, junho. Disponível em: $\quad$ https://www3.ufrb.edu.br/seer/index.php/griot/article/download/801/514/. Acesso em 10 mai. 2020.

QUINTELA, Adroaldo et al. (2020). Celso Furtado: os combates de um economista. São Paulo: Fundação Perseu Abramo: Expressão Popular.

RICUPERO, Bernardo (2020). Celso Furtado e o pensamento social brasileiro. In: SOUSA, Cidoval Morais de; THEIS, Ivo Marcos; BARBOSA, José Luciano Albino (Orgs.). Celso Furtado: a esperança militante (interpretações). v. 1. Campina Grande: EDUEPB

ROCHA, Maria Eduarda da Mota (2012). Celso Furtado e a formação da cultura brasileira. Revista de Economía Politica de las Tecnologias de la Información y de la Comunicación, São Cristovão, v. 14, n.1, ene./abr. Disponível em: https://seer.ufs.br/index.php/eptic/article/view/399/324. Acesso em 04 mai. 2020.

RODRÍGUEZ, Octavio (2009). O estruturalismo latino-americano. Rio de Janeiro: Civilização Brasileira.

\& BURGUEÑO, Óscar (2007). Desenvolvimento e cultura: notas sobre o enfoque de Celso Furtado. In: SABOIA, J.; CARVALHO, F. C. (Orgs.). Celso Furtado e o século XXI. Rio de Janeiro: Instituto de Economia/UFRJ.

SANTAELLA, Lúcia (2003). Cultura e artes do pós-humano: da cultura da mídia à cibercultura. São Paulo: Paulus.

SANTOS, Fábio Pádua dos (2011). O enfoque histórico-estrutural e a crítica relegada. Textos de Economia, Florianópolis: v.14, n.1, p. 51-81, jan./jul. Disponível em: https://periodicos.ufsc.br/index.php/economia/article/view/21758085.2011v14n1p51. Acesso em 14 abr. 2020.

SEVERINO, Antônio Joaquim (2011). Do ensino da filosofia: estratégias interdisciplinares. Educação em Revista, Marília: v.12, n.1, p. 81-96, jan./jun. Disponível

em: http://www2.marilia.unesp.br/revistas/index.php/educacaoemrevista/article/view/1 539/1333. Acesso em 16 abr. 2020.

SILVA, Frederico (2007). Política cultural no Brasil, 2002-2006: acompanhamento e análise. In: BRASIL. Ministério da Cultura. Instituto de Economia Aplicada. Coleção cadernos de políticas culturais. Brasília: Ministério da Cultura. v. 2.

SOUSA, Cidoval Morais de; THEIS, Ivo Marcos; BARBOSA, José Luciano Albino (Orgs.) (2020). Celso Furtado: a esperança militante (interpretações). v. 1. Campina Grande: EDUEPB. 
SUNKEL, Osvaldo \& PAZ, Pedro (1970). El subdesarrollo latinoamericano y la teoría del desarrollo. Mexíco, DF: Siglo XXI.

WEBER, Max (1967). A ética protestante e o espírito do capitalismo. São Paulo: Pioneira.

. (1992). Metodologia das Ciências Sociais. 2 vols. São Paulo: Cortez e editora UNICAMP.

Artigo recebido em 14 de julho de 2020.

Aprovado em 06 de novembro de 2020.

DOI: $10.12957 /$ intellectus.2020.52742 